Article

\title{
Understanding Household Energy Transitions: From Evaluating Single Cookstoves to "Clean Stacking" Alternatives
}

\author{
Paulo Medina ${ }^{1}$, Victor Berrueta ${ }^{2}$, Lourdes Cinco ${ }^{3}$, Victor Ruiz-García ${ }^{1}$, Rufus Edwards ${ }^{4}$, \\ Belén Olaya ${ }^{1}$, Astrid Schilmann ${ }^{5}$ and Omar Masera ${ }^{1, * \mathbb{C}}$
}

1 Laboratorio de Bioenergía, Laboratorio de Innovación y Evaluación de Estufas de Biomasa (LINEB), Instituto de Investigaciones en Ecosistemas y Sustentabilidad (IIES), Universidad Nacional Autónoma de México (UNAM), Morelia, Michoacán 58190, Mexico; paulo491@hotmail.com (P.M.);

vruiz@cieco.unam.mx (V.R.-G.); b.olaya@cieco.unam.mx (B.O.)

2 Grupo Interdisciplinario de Tecnología Rural Apropiada A.C. (GIRA), Pátzcuaro, Michoacán 61613, Mexico; vberrueta@gira.org.mx

3 Facultad de Ingeniería Química, Universidad Michoacana de San Nicolás de Hidalgo, Morelia, Michoacán 58030, Mexico; lourdescincoizq@gmail.com

4 Department of Epidemiology, School of Medicine, University of California Irvine, Irvine, CA 92697-3957, USA; edwardsr@uci.edu

5 Dirección de Salud Ambiental, Centro de Investigación en Salud Poblacional, Instituto Nacional de Salud Pública, Cuernavaca, Morelos 62100, Mexico; aschilmann@insp.mx

* Correspondence: omasera@gmail.com

Received: 15 August 2019; Accepted: 5 November 2019; Published: 10 November 2019

check for updates

\begin{abstract}
The pervasiveness of "stacking" between traditional and clean fuels/stoves is moving the household clean cooking research and policy agenda from programs that are centered on one-fuel or stove, to multi-clean fuel/device interventions that could result in a more effective displacement of traditional biomass stoves. However, there is little recognition and knowledge of the benefits realistic clean-stacking cooking solutions can have on indoor air quality and health. In this paper, particulate matter $\left(\mathrm{PM}_{2.5}\right)$ and carbon monoxide $(\mathrm{CO})$ concentration levels that are associated with stove-stacking options (Patsari-U-shaped open fire (U-type), Patsari-liquefied petroleum gas (LPG) stove, U-type-LPG, and Patsari-U-type-LPG) common within rural Mexico were evaluated while using a controlled cooking cycle (CCC) from the Purepecha Highlands, which mimics the most common dishes prepared daily within the region as well as their sequential arrangement. The results confirms that the WHO Interim Target-1 (IT1) of $35 \mu \mathrm{g} / \mathrm{m}^{3}$ for $\mathrm{PM}_{2.5}$ is exceeded whenever woodburning open fires are part of the stacking combination (Patsari-U-type $107 \pm 9 \mu \mathrm{g} / \mathrm{m}^{3}$, U-type-LPG $131 \pm 55 \mu \mathrm{g} / \mathrm{m}^{3}$ and Patsari-U-type-LPG $107 \pm 22 \mu \mathrm{g} / \mathrm{m}^{3}$ ). However, well-designed and properly operated woodburning chimney stoves, such as the Patsari can meet the IT1, either used exclusively $\left(21 \pm 8 \mu \mathrm{g} / \mathrm{m}^{3}\right)$ or as a "clean stacking" option with LPG $\left(24 \pm 5 \mu \mathrm{g} / \mathrm{m}^{3}\right)$. Given stove stacking patterns, evaluating the health and environmental consequences of stove transitions while assuming the total replacement of traditional fires by clean cooking options will lead to misplaced expectations, and programs should evaluate more realistic "clean-stacking" options.
\end{abstract}

Keywords: woodburning plancha-type Stoves; clean stacking; LPG; IAP; $\mathrm{PM}_{2.5}$

\section{Introduction}

Nearly three billion people, mostly rural (90\%) and poor, lack access to clean cooking devices [1]. The reliance on polluting devices to meet household energy needs is a leading cause of indoor air 
pollution (IAP), which results in millions of deaths worldwide [2], among other severe environmental and social impacts. National and international programs that are designed to address these health concerns have focused on transitioning households towards cleaner energy practices by encouraging access to improved woodburning stoves (ICS), and increasingly by promoting exclusive use of other fuels, such as liquefied petroleum gas (LPG), electricity, biogas, and other options. However, increasing access to clean technologies and fuels rarely results in their consistent, exclusive, and long-term use in poor, rural communities [3,4]. On the contrary, the norm is stacking (defined here as the combined use of stoves and fuels) of clean fuels with traditional devices, as in most household energy transitions, full uptake and sustained use of non-traditional clean cooking alternatives has been low, and the transitions only partial [5,6].

Under these circumstances, the policy agenda needs to shift from promoting the exclusive use of clean fuels and stoves to promoting "clean stacking" options. However, little research has been conducted so far in this area. Specifically, the IAP implications of stacking traditional and clean stoves, or stacking different clean fuels and devices (e.g., ICS and LPG), have not been examined in detail. We do not know, for example, what combination of stoves/cooking practices help to achieve the World Health Organization (WHO) indoor air quality guidelines.

Mexico constitutes a good case study to advance our knowledge on the potential benefits and challenges of clean stacking alternatives for household cooking. In Mexico, 28 million people, encompassing $90 \%$ of rural households and a significant fraction of peri-urban households, still use fuelwood in traditional open fires as their main cooking option [7]. There has also been a significant and increasing penetration of LPG in rural areas since the 70s, but LPG has been documented to be almost always used in stacking [8], with wood in open fires and improved stoves [3]. More recently, microwave ovens are increasingly prevalent in more affluent rural households. Since the mid-2000s, the National Government has disseminated more than one-million "plancha-type chimney stoves" (plancha-type stoves are characterized as having a large flat griddle, named "plancha" or "comal" that covers the upper part of the stove, avoiding the direct contact between the fire and the pot and, also allowing the smoke to exit the house through a chimney. The griddle is typically made of metal, and the stoves could be metallic or made of local materials, like bricks, mud, and cement [9]) that range from built in-situ to mass-produced. The Patsari Stove, developed by our research group, has been widely disseminated reaching more than 250,000 households throughout the country [7]. In this regard, the National ICS program was launched to mitigate greenhouse emissions associated to the non-sustainable use of fuelwood and is included within the National Climate Change Action. A study by the World Bank identified ICS as the largest mitigation option within the Mexican residential sector in the period between the years 2009 and 2024 [7]. As a result of these different interventions, diverse and complex fuel/device stacking patterns are currently present within households that have progressed from exclusive use of traditional open stone fires to stove stacking combinations, including traditional, LPG, and Patsari plancha-type stoves [10,11]. Rural households also show definite stove preferences in performing the wide range of cooking tasks. While Patsari stoves are used to fry food and mainly to make tortillas [10], LPG is mostly used to reheat tortillas and fry eggs [4]. Boiling beans, making nixtamal (that is prepared by cooking grains of corn over a low flame [12]) and heating water for bathing are usually performed on the open fire [12]. Further, cooking tasks are usually performed in a "cooking cycle" [13], which frequently involves simultaneous cooking tasks on different stoves to minimize fuel consumption and reduce the time for cooking.

Many unvented improved woodburning stoves do not meet WHO indoor air quality guidelines [14]. As a consequence, international efforts have shifted to promoting exclusive use of fuels that are "clean" at a household level, such as LPG. However, as stated above, there is increasing evidence worldwide showing that, as in Mexico, economic, cultural, logistic, and other circumstances lead households to largely stack clean fuels with solid biomass stoves, and in these contexts, the exclusive use of clean fuel is an exception rather than the norm [15]. 
Under these circumstances, evaluating the health and environmental consequences of stove transitions based on simple replacement will lead to misplaced expectations. Therefore, it is critical to re-assess which stove stacking combinations are "clean" and meet international guidelines intended to protect health. However, little research has been conducted to show the impact of different stacking patterns of stoves and fuels on IAP. Within Latin America, improved woodburning chimney stoves constitute, by far, the most common type of cookstove intervention. In this paper, we report particulate matter $\left(\mathrm{PM}_{2.5}\right)$ and carbon monoxide (CO) kitchen concentrations from the stacking of improved plancha stoves with other stoves and clean fuels that are common in Mexico to identify "clean stacking" combinations and characterize their performance in relation to international guidelines.

\section{Materials and Methods}

To determine the typical stove stacking combinations, a thorough review of existing data-bases from the Purepecha Region of Mexico was conducted to investigate: (a)the typical daily dishes prepared by an average household; and (b)the most common stacking options, and how different dishes were allocated to each stove depending on the type of stack (e.g., where are tortillas made in case stacking between open fires and LPG or between ICS and LPG, and so on). Based on this information, a controlled cooking cycle (CCC) was developed that reflects regionally representative daily food consumption for a family of four people. The CCC was conducted by a local cook in a simulated kitchen to evaluate the impacts of different stacking options, whilst controlling kitchen size, ventilation, and other characteristics that differ between households.

\subsection{Review and Re-Processing of a Comprehensive Field Survey}

Stove use patterns in 257 rural households were reviewed, as a part of a health study by the National Institute of Public Health (INSP) in the Purepecha Highlands, which also served as the basis for identifying stove adoption and usage intensity of improved plancha stoves, and the current models of cookstove adoption [4]. Participants in a community trial to evaluate the health impact of the introduction of improved biomass stoves received a Patsari stove at the beginning of 2005 (intervention group) or at mid of 2006 (control group) [16]. Subsequently, a follow-up study was

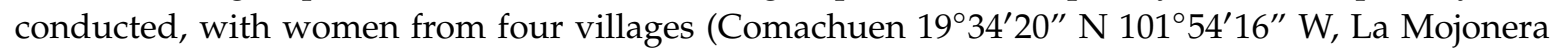
$19^{\circ} 42^{\prime} 01^{\prime \prime} \mathrm{N} 101^{\circ} 50^{\prime} 01^{\prime \prime} \mathrm{W}$, Quinceo $19^{\circ} 44^{\prime} 07^{\prime \prime} \mathrm{N} 101^{\circ} 13^{\prime} 27^{\prime \prime} \mathrm{W}$, and Turicuaro $19^{\circ} 34^{\prime} 14^{\prime \prime} \mathrm{N} 101^{\circ} 56^{\prime} 18^{\prime \prime}$ W. Figure S1 shows Purepecha region of Michoacan State where these communities are located), who previously participated in the community trial, by previously trained field workers. Information regarding stove use was collected while using a structured interview in the participant's house to register retrospective information since February 2005 to October 2012-August 2013 [17]. For this article, we analyze the data on: (i) the main cooking tasks, their frequency, and the way that they are integrated in typical daily cooking cycles, (ii) the different stove stacking options present in the sample, and (iii) the main cooking practices conducted with each stove according to the different stacking options.

\subsection{Tests of Clean Stacking Options in Simulated Kitchen}

Simulated kitchen. All of the tests were carried out in a simulated kitchen at GIRA in Patzcuaro, Michoacan, Mexico, which is representative-in terms of materials, size, volume, and air exchange rates—of the rural kitchens present in the Region (See, Figures S2 and S3). The simulated kitchen has the following internal dimensions: $4.3 \mathrm{~m}$ wide by $3.20 \mathrm{~m}$ in length, with a volume kitchen of $41 \mathrm{~m}^{3}$ and an air exchange rates of $40 / \mathrm{h}$. The simulated kitchen design allows for investigators changes to the layout and size of the openings, so that the air exchange rates can be controlled.

Stoves. Figure 1a,b shows the stoves tested: Patsari plancha-type stove, a traditional U-shaped open fire (U-type), LPG stove and four stove stacking: Patsari-U-type, Patsari-LPG, U-type-LPG, and Patsari-U-type-LPG. 


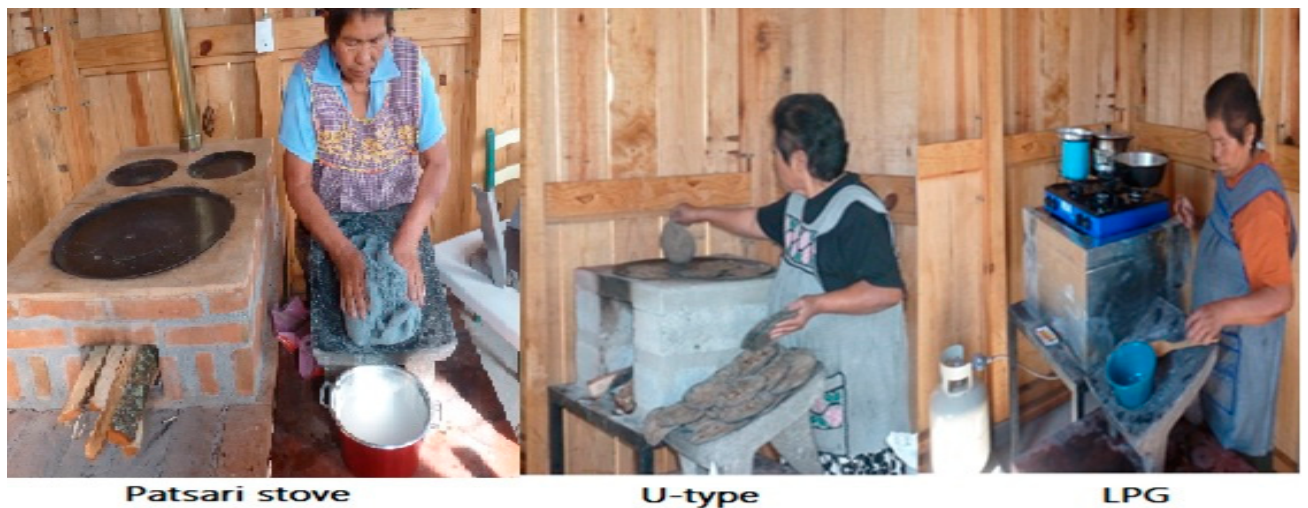

(a)

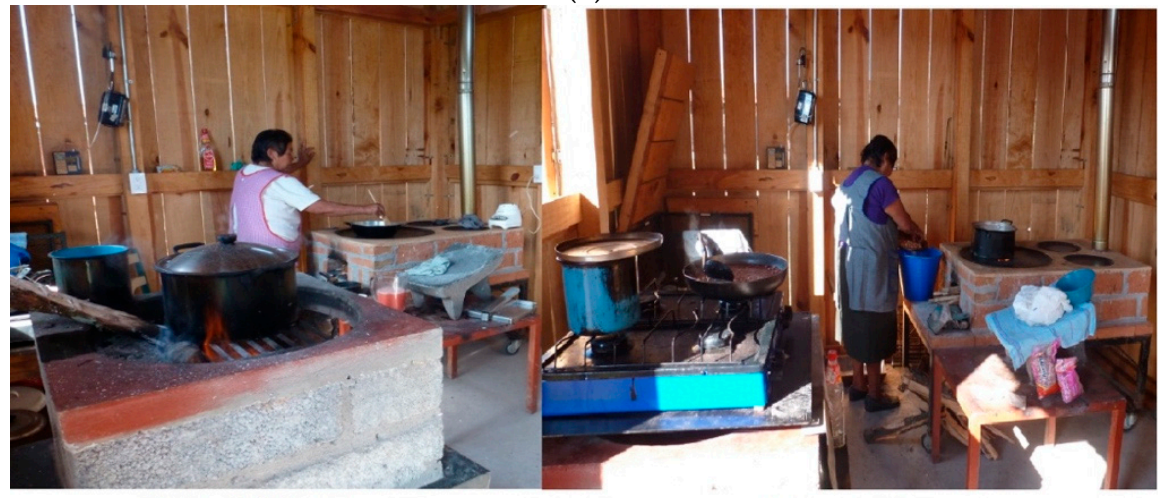

Patsari-U-type

Patsari-LPG

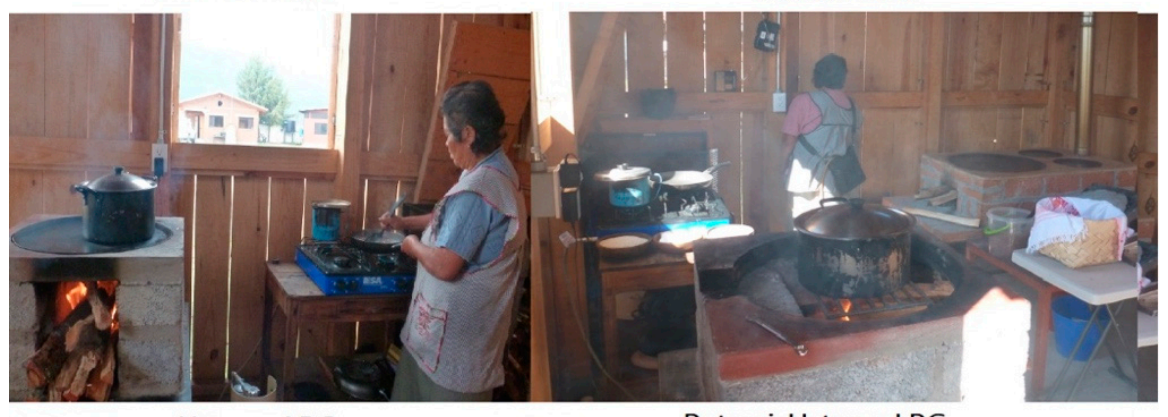

U-type-LPG

Patsari-U-type-LPG

(b)

Figure 1. (a) Cookstoves tested: Patsari, U-type, and LPG. (b) Cookstove Stacking options. The Figure shows the cook conducting a controlled cooking cycle (CCC) in the simulated kitchen for each of the four combinations (stacking) of stoves tested: Patsari-U-type, Patsari-LPG, U-type-LPG, and Patsari-U-type-LPG. Table 1 describes the dishes that were prepared with each stove, depending on the stacking option.

Table 1. Cooking tasks included in the CCC and their distribution according to each stacking option.

\begin{tabular}{lcccc}
\hline \multirow{2}{*}{ Cooking Task } & \multicolumn{4}{c}{ Stacking Option } \\
\cline { 2 - 5 } & Patsari-U-Type & Patsari-LPG & LPG-U-Type & Patsari-LPG-U-Type \\
\hline 1. Tortillas & Patsari & Patsari & U-type & Patsari \\
2. Fried rice & Patsari & Patsari & U-type & Patsari \\
3. Boil beans & U-type & Patsari & U-type & U-type \\
4. Boil 1 L of water & Patsari & LPG & LPG & LPG \\
5. Reheat (tortillas and meals) & Patsari & LPG & LPG & LPG \\
6. Fried meals (eggs and beans) & Patsari & LPG & LPG & LPG \\
\hline
\end{tabular}

NOTE: Within "stacking option" we include both the exclusive use of each stove and the combinations with other stoves. The table shows the cooking tasks performed in each stove depending on the stacking option. Five controlled cooking cycle (CCC) tests were conducted for each individual stove and for each stacking option. 
Controlled Cooking Cycle (CCC). Six main dishes (or cooking practices) were identified through the Regional field survey described above: tortillas, fried meals (eggs and beans), fried rice, boiling water for beverages, boiling beans, and reheating. Local people integrate these dishes into a specific arrangement-in terms of amount of food prepared for each dish and the sequencing of each practice-or a daily "cooking cycle". Additionally, when stoves are stacked, the allocation of stoves to each cooking practice depends on the specific stacking option. With this information, a controlled cooking cycle (CCC) was defined, (see Medina et al. [18] for a more detailed definition and description of the CCC) to mimic and standardize how the users cook their meals and also the way that each dish is accommodated in the different stoves according to the specific stacking options, as reported in Table 1. The CCC included: (i) $3 \mathrm{~kg}$ of tortillas, (ii) boil $1 \mathrm{~kg}$ of beans, (iii) fried eggs (five pieces) and $\frac{1}{2} \mathrm{~kg}$ of beans, (iv) $\frac{1}{2} \mathrm{~kg}$ of fried rice, (v) $1 \mathrm{~L}$ of boiled water, and (vi) reheat $1 \frac{1}{2} \mathrm{~kg}$ of tortillas and fried dishes (see Figure S4). Both of the dishes selected and their amounts are in good agreement with previous publications on the subject (see, for example Masera-Navia [12] and Medina et al. [18]). We performed five CCC tests in each of the three individual stoves and four stacking options. In addition, two individual and short-time cooking practices that are important were also measured: reheat meals and making nixtamal/heating water for bathing.

Fuels. White oak (Quercus bicolor) was used in all CCC and individual tests; the average dimensions of fuel were $3 \mathrm{~cm} \times 5 \mathrm{~cm} \times 30 \mathrm{~cm}$, and a digital scale with $1 \mathrm{~g}$ resolution was used to determine the fuelwood measurements. The fuel moisture content was measured with a Protimeter Timbermaster Wood Moisture Meter, as reported by Pennise et al. [19], and the average fuelwood moisture content for all tests was $11 \pm 2 \%$, being expressed as wet basis with a range of (8-15\%). For LPG stove, a gas cylinder of $19 \mathrm{~kg}$ (fuel + cylinder) was used to perform cooking tasks while using a digital scale with $10 \mathrm{~g}$ resolution to measure initial and final gas consumption. CCC and individual tests were initiated with a small amount $(25 \mathrm{~g})$ of "ocote", that is a highly resinous piece of pitch pine, for Patsari and U-type stoves and kitchen matches for LPG stove were used as the fire starter material.

Cook. A local cook was hired to perform all of the CCC and individual tests, as can be seen in Figure 1a,b. The same sequence of cooking tasks was followed for each CCC and stacking option. Indoor air monitoring was performed from November 2018 to February 2019. The average climate in Patzcuaro, Michoacan, Mexico during this period was $\mathrm{T}_{\min }=4{ }^{\circ} \mathrm{C}, \mathrm{T}_{\max }=29^{\circ} \mathrm{C}$, with average precipitation of $13.7 \mathrm{~mm}$.

\subsection{Air Sampling Methods}

Ambient concentrations of $\mathrm{PM}_{2.5}$ and $\mathrm{CO}$ were monitored outside the kitchen during the whole study period. $\mathrm{PM}_{2.5}$ and $\mathrm{CO}$ were monitored inside the kitchen during controlled cooking cycles. The average concentration during the cooking event was time-weighted with ambient concentrations during the non-cooking time in the 24-h period to obtain average 24-h average kitchen concentrations. During non-cooking events significant differences between $\mathrm{PM}_{2.5}$ and $\mathrm{CO}$ concentrations indoors and outdoors of the simulated kitchen during 24-h periods were not observed (six simultaneous 24-h measurements while using 2 Haz-Scanner IEMS (SKC Inc. V.5.1.5): $p$ values $=0.23$ and 0.61 for $\mathrm{PM}_{2.5}$ and $\mathrm{CO}$, respectively).

Kitchen concentrations. Real-time indoor concentrations of $\mathrm{PM}_{2.5}$ and $\mathrm{CO}$ from cooking periods (e.g., CCCs and individual tasks) were determined while using Aprovecho Research Center 5000 series Indoor Air Pollution (IAP) meters. The 5000 series IAP meters use a light scattering sensor and an electrochemical cell to measure the $\mathrm{PM}_{2.5}$ and $\mathrm{CO}$ concentrations, respectively, and they have been utilized in similar studies [20-22]. In this study, IAP meters were calibrated according to manufacturer specifications [23] in a well-ventilated location while using zero air and a mixture of $500 \mathrm{ppm} \mathrm{CO/5000}$ ppm $\mathrm{CO}_{2}$ (Praxair Technology, Inc., Danbury, CT, USA) and continuous measurements were recorded every nine seconds. Three IAP meters were installed in the simulated kitchen (Figure S5), according to recommendations that were developed for the HEH projects by Smith et al. [24], and subsequent Berkeley Air Standard Operating Procedure [25]. Gravimetric $\mathrm{PM}_{2.5}$ samples were collected on $37 \mathrm{~mm}$ 
Teflon filters (SKC Inc., Eighty Four, PA, USA) while using air sampling pumps (Model 224-PCXR8; SKC Inc., Eighty Four, PA, USA) with $\mathrm{PM}_{2.5}$ cyclones (Aluminum Respirable Dust Cyclone; SKC Inc., Eighty Four, PA, USA) using a flow rate of $4 \mathrm{~L} / \mathrm{min}$. The flow rates were measured before and after sampling measurements while using a Primary Flow Meter (Mesa Labs Bios Defender 520-M, Brandt Instruments, Prairieville, LA, USA). The filters were equilibrated for 48 -h at $21 \pm 2{ }^{\circ} \mathrm{C}$ and $35 \pm 5 \%$ relative humidity. The filters were automatically weighed immediately after equilibrium periods using an electronic analytical microbalance with $1 \mu \mathrm{g}$ readability (Mettler-Toledo $\mathrm{GmbH}$, model XPR10 8606, Greifensee, Switzerland) and an antistatic neutralizer (Sartorius-pen YSTP01, Sartorius, AG, Germany) to eliminate the static charge. Each filter was weighed five times and its weight was accepted if it was within a range of two micrograms. The filters were weighed before and after the sampling according to the national standards of air quality for particulate matter by Environmental Protection Agency (EPA) [26]. The microbalance calibration was verified during each weighing session while using standard calibration weights from $1 \mathrm{mg}$ to $5 \mathrm{~g}$ (Sartorius YCS011-352-00, Sartorius, AG, Germany). Blank laboratory filters were used to maintain quality control during each weighing. Preand post-filter weighing were both performed by the same analyst.

Ambient 24-h concentrations. A Haz-Scanner IEMS (SKC Inc. V.5.1.5) was used to measure the ambient concentrations of $\mathrm{PM}_{2.5}$ and $\mathrm{CO}$ every minute outside the kitchen for 24-h periods from the beginning to the end of the study. The $\mathrm{CO}$ sensor was calibrated in a well-ventilated room while using a reference gas of 500 ppm CO (Praxair Technology, Inc.). Gravimetric PM $_{2.5}$ samples from ambient air were also measured for 8-h periods using the same equipment and protocol mentioned before.

\subsection{Data Analysis}

Statistical analysis of difference in means was conducted with a two-sample $t$-test. More details regarding the statistical tests performed are presented in $[9,18]$.

\section{Results}

\subsection{Patterns of Stoves Use and Distribution of Cooking Practices}

Figure 2 shows the stove and fuel combinations used in 257 rural households followed over a nine-year period: $37 \%$ exclusively rely on three stone fire (TSF); $17 \%$ make exclusive use of Patsari stoves; and, only $1 \%$ make exclusive use of LPG. In total, $45 \%$ households stack their stoves, mostly in the form of Patsari-TSF (37\% of total households), Patsari-LPG (3\%); (TSF-LPG (3\%) and Patsari-TSF-LPG (2\%). Figures S6-S9 show the distribution of cooking tasks (such as tortillas, beans, nixtamal, etc.) by stove and stacking option for the cases of Patsari-TSF, Patsari-LPG, TSF-LPG, and LPG-Patsari-TSF. Stove preferences vary by cooking practice and also "shift", depending on the specific staking option.

For example, TSF are preferred for the more fuel and time-intensive practices (such as nixtamal, beans, and tortillas when no other option or LPG is present) and they are almost exclusively used for heating water for bathing. LPG stoves are preferred for reheating dishes or for preparing quick meals, such as heating water for coffee or milk in the morning. Patsari stoves, on the other hand, are preferred for making tortillas and other meals, even when stacked with TSF. When both Patsari and LPG are present TSF are used only for heating water for bathing and for nixtamal, both of which are usually performed outside the kitchen and non-daily. The different cooking practices also have different implications in terms of IAP. For example, tortilla making requires substantial time and it also requires the cook to be in close proximity to the stove, which suggests that the displacement of this task might have important implications in the reduction of exposures of cooks. 


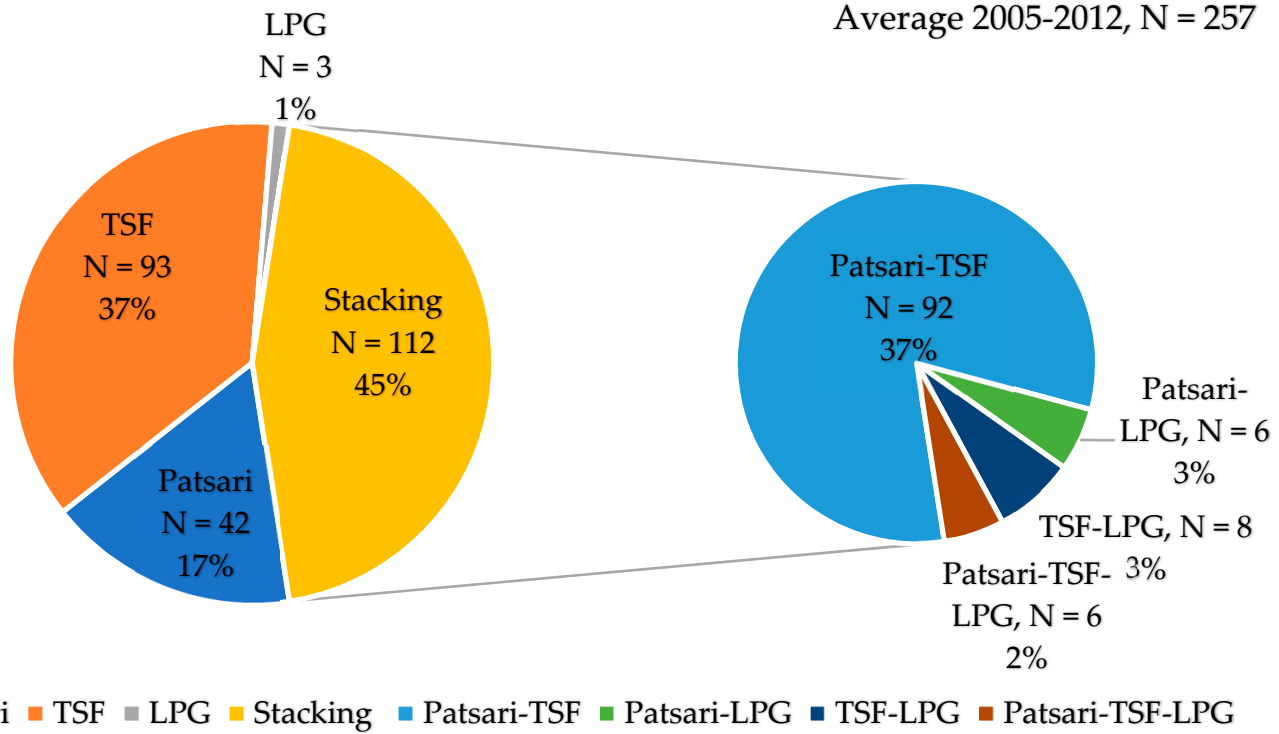

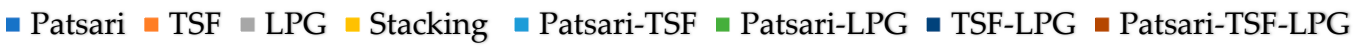

Figure 2. Average patterns of stove and fuels use from the year 2005 to 2012. Source: Field Survey.

\subsection{Indoor Air Pollution Levels}

Table 2 shows the $\mathrm{PM}_{2.5}$ and $\mathrm{CO}$ 24-h concentrations that result from performing the CCC in each individual stove and for the four stacking options. The lowest $24 \mathrm{~h}$ concentrations for both pollutants were obtained for LPG with $18 \pm 4 \mu \mathrm{g} / \mathrm{m}^{3}$ and $0.6 \pm 0.3 \mathrm{mg} / \mathrm{m}^{3}$ for $\mathrm{PM}_{2.5}$ and CO, respectively, Patsari $21 \pm 8 \mu \mathrm{g} / \mathrm{m}^{3}$ and $1.7 \pm 0.5 \mathrm{mg} / \mathrm{m}^{3}$, and Patsari-LPG $24 \pm 5 \mu \mathrm{g} / \mathrm{m}^{3}$ and $3 \pm 1 \mathrm{mg} / \mathrm{m}^{3}$. For the U-type, a concentration of $144 \pm 46 \mu \mathrm{g} / \mathrm{m}^{3}$ was found for $\mathrm{PM}_{2.5}$ which is in a good agreement with the values that were reported by Armendáriz-Arnez et al. [27]. Figure 3 shows a plot of $\mathrm{PM}_{2.5}$ against $\mathrm{CO} 24-\mathrm{h}$ concentrations for each stove and stacking option, highlighting the region within which the stoves will meet the IT1 for $\mathrm{PM}_{2.5}\left(35 \mu \mathrm{g} / \mathrm{m}^{3}\right)$ and the WHO Air Quality Guideline (AQG) for CO $\left(7 \mathrm{mg} / \mathrm{m}^{3}\right)$. It is interesting to see that three options-Patsari, LPG, and the stacking Patsari-LPG-meet both IT1 and AQG targets.

Table 2. Average cooking, 24-h, ambient air and stove contribution concentrations of $\mathrm{PM}_{2.5}$ and $\mathrm{CO}$ by CCC.

\begin{tabular}{cccccccccc}
\hline & & \multicolumn{3}{c}{ Particulate Matter $\mathbf{P M}_{\mathbf{2 . 5}}\left(\boldsymbol{\mu g} / \mathbf{m}^{\mathbf{3}}\right)$} & \multicolumn{3}{c}{ Carbon Monoxide CO $\left(\mathbf{m g} / \mathbf{m}^{\mathbf{3}}\right)$} \\
\cline { 3 - 9 } Task & Stove/Stacking & $\begin{array}{c}\text { Total } \\
\text { Cooking }\end{array}$ & $\mathbf{2 4 - h}$ & $\begin{array}{c}\text { Ambient } \\
\text { Air }\end{array}$ & $\begin{array}{c}\text { Incremental } \\
\text { Stove } \\
\text { Contribution }\end{array}$ & $\begin{array}{c}\text { Total } \\
\text { Cooking }\end{array}$ & $\begin{array}{c}\text { 24-h } \\
\text { Ambient } \\
\text { Air }\end{array}$ & $\begin{array}{c}\text { Incremental } \\
\text { Stove } \\
\text { Contribution }\end{array}$ \\
\hline \multirow{4}{*}{ CCC } & Patsari & $29 \pm 12$ & $21 \pm 8$ & $19 \pm 11$ & $6 \pm 2$ & $2.7 \pm 0.3$ & $1.7 \pm 0.5$ & $1.1 \pm 0.4$ & $0.8 \pm 0.2$ \\
& U-type & $874 \pm 177$ & $144 \pm 46$ & $16 \pm 11$ & $132 \pm 44$ & $12 \pm 2$ & $3 \pm 1$ & $0.7 \pm 0.3$ & $2.8 \pm 0.7$ \\
& LPG & $38 \pm 12$ & $18 \pm 4$ & $14 \pm 4$ & $4 \pm 3$ & $2.8 \pm 1.2$ & $0.6 \pm 0.3$ & $0.2 \pm 0.2$ & $0.4 \pm 0.3$ \\
& Patsari-U-type & $610 \pm 72$ & $107 \pm 9$ & $13 \pm 6$ & $97 \pm 9$ & $11 \pm 1$ & $2.7 \pm 0.3$ & $0.9 \pm 0.1$ & $1.7 \pm 0.3$ \\
& Patsari-LPG & $53 \pm 8$ & $24 \pm 5$ & $18 \pm 6$ & $9 \pm 1$ & $4 \pm 1$ & $3 \pm 1$ & $2 \pm 1$ & $0.6 \pm 0.1$ \\
& U-type-LPG & $868 \pm 420$ & $131 \pm 55$ & $10 \pm 7$ & $124 \pm 56$ & $21 \pm 7$ & $4 \pm 1$ & $1 \pm 0.1$ & $2.8 \pm 0.9$ \\
& Patsari-U-type-LPG & $718 \pm 146$ & $107 \pm 22$ & $17 \pm 9$ & $93 \pm 26$ & $22 \pm 2$ & $3.2 \pm 0.2$ & $0.5 \pm 0.3$ & $2.8 \pm 0.3$ \\
\hline
\end{tabular}

NOTES: Variability expressed as \pm 1 standard deviation. The table shows the IAP concentrations resulting from performing 5 CCC tests to each stove and stacking option. The "Total cooking" columns show the average pollutant concentration during the whole cooking event; the "Incremental stove contribution" columns are the difference between the "total cooking" and "ambient air" columns. 


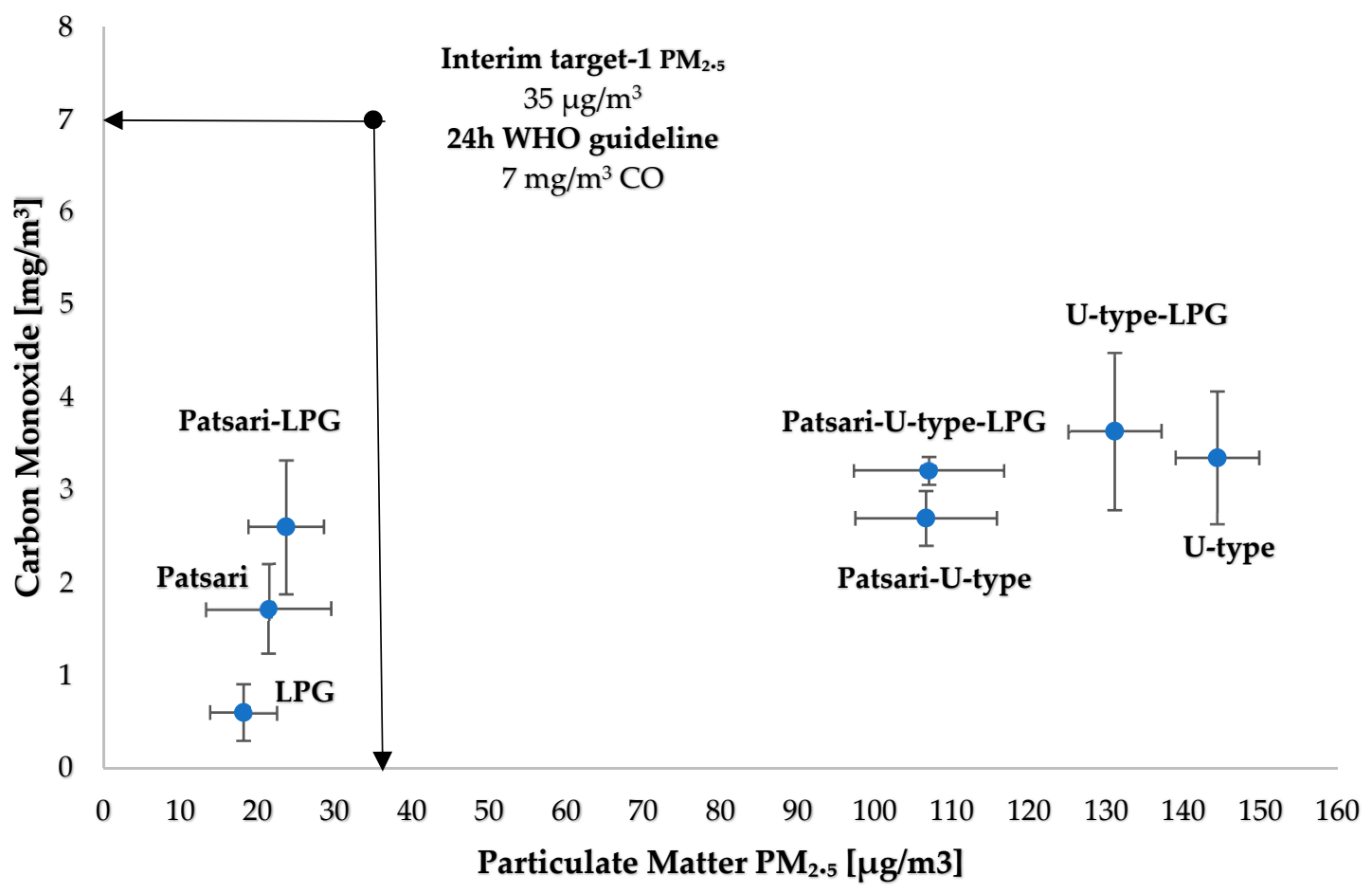

Figure 3. Average 24-h $\mathrm{CO}$ and $\mathrm{PM}_{2.5}$ concentrations for CCC. The blue dots represent concentration averages and whiskers are \pm 1 standard deviation of the measurements.

\subsection{Fuel, Time, and Energy Consumption}

Table 3 shows fuel consumption, cooking duration, and energy consumption associated with different stoves and stacking options. The U-type showed larger fuelwood and energy consumption to complete the CCC with $16 \pm 1 \mathrm{~kg}$ and $276 \pm 18 \mathrm{MJ}$, respectively (Table 3). In single stove/fuel comparisons, the Patsari stove demonstrated statistically significant fuel and energy savings of $31 \%$ $(p<0.01, \alpha=0.01)$ when compared to the U-type, and the LPG stove demonstrated a reduction of $84 \%$ in energy consumption relative to the traditional U-type open fire. Unfortunately, in actual practice, these very large LPG energy savings are never realized, as rural people do not make exclusive use of LPG.

However, among the stacking options the Patsari-LPG stacking option was shown to consume the least energy, with a significant $56 \%$ reduction in fuelwood and $53 \%$ reduction in energy savings as compared to the traditional U-type open fire. In contrast, the LPG-U-type only resulted in reductions of $25 \%$ in fuel consumption and $19 \%$ in energy consumption. The three-stove combination (Patsari-U-type-LPG) resulted in negligible fuel savings and almost the same energy use than the U-type alone. Figure 4 shows $24-\mathrm{h} \mathrm{PM}_{2.5}$ concentrations and cooking times for each stove type and stacking combination. The Patsari stove had longer cooking time in the CCC with $305 \pm 25 \mathrm{~min}$, which is in a good agreement with the times reported in-field [28]. By using Patsari-U-type stacking, a significant reduction in cooking time was observed of 38\%- and 33\%-time savings relative to Patsari and U-type, respectively. Patsari-U-type-LPG saved $45 \%, 40 \%$, and $37 \%$ relative to individual use of Patsari, U-type, and LPG alone, respectively. The use of stacking options represents a significant time savings for users, and thus a potentially important motivation. In agreement with box model results of Johnson et al. [29] using water boiling tests emission data, measurements of $\mathrm{PM}_{2.5}$ in a simulated kitchen show that use of open fires inside the kitchen represents a significant health risk, even when it is only used for short-time tasks, such as nixtamal and heating water for bathing (see Tables S1 and S2). 
Table 3. Fuel, time, and energy consumption for CCC.

\begin{tabular}{|c|c|c|c|c|c|}
\hline Task & Stove/Stacking & Fuel & $\begin{array}{c}\text { Fuel } \\
\text { Consumption } \\
(\mathrm{kg})\end{array}$ & $\begin{array}{c}\text { Energy } \\
\text { Consumption } \\
\text { (MJ) }\end{array}$ & $\begin{array}{l}\text { Cooking } \\
\text { Time (min) }\end{array}$ \\
\hline \multirow{16}{*}{$\mathrm{CCC}$} & Patsari & Fuelwood & $11 \pm 1$ & $189 \pm 21$ & $305 \pm 25$ \\
\hline & U-type & Fuelwood & $16 \pm 1$ & $276 \pm 18$ & $283 \pm 20$ \\
\hline & LPG & Gas & $0.9 \pm 0.2$ & $43 \pm 8$ & $268 \pm 81$ \\
\hline & \multirow{3}{*}{ Patsari-U-type } & Fuelwood, Patsari & $5 \pm 2$ & $94 \pm 31$ & $162 \pm 10$ \\
\hline & & Fuelwood, U-type & $10 \pm 1$ & $171 \pm 16$ & $189 \pm 16$ \\
\hline & & TOTAL & $15 \pm 3$ & $266 \pm 46$ & $189 \pm 16$ \\
\hline & \multirow{3}{*}{ Patsari-LPG } & Fuelwood & $7 \pm 1$ & $125 \pm 10$ & $215 \pm 17$ \\
\hline & & Gas & $0.1 \pm 0.1$ & $6 \pm 1$ & $43 \pm 4$ \\
\hline & & TOTAL & $7 \pm 1$ & $131 \pm 12$ & $215 \pm 17$ \\
\hline & \multirow{3}{*}{ U-type-LPG } & Fuelwood & $12 \pm 1$ & $218 \pm 10$ & $212 \pm 17$ \\
\hline & & Gas & $0.1 \pm 0.1$ & $5 \pm 1$ & $36 \pm 2$ \\
\hline & & TOTAL & $12 \pm 1$ & $223 \pm 11$ & $212 \pm 17$ \\
\hline & \multirow{4}{*}{ Patsari-U-type-LPG } & Fuelwood, Patsari & $4 \pm 2$ & $77 \pm 26$ & $107 \pm 15$ \\
\hline & & Fuelwood, U-type & $10 \pm 1$ & $169 \pm 15$ & $169 \pm 15$ \\
\hline & & Gas & $0.1 \pm 0.1$ & $6 \pm 1$ & $35 \pm 7$ \\
\hline & & TOTAL & $14 \pm 3$ & $251 \pm 41$ & $169 \pm 15$ \\
\hline
\end{tabular}

NOTE: Variability expressed as \pm standard deviation. Total cooking time shown here is the time users devote to prepare the CCC. As stoves are used many times in parallel, the total time needed to complete a CCC is not simply the addition of the time each stove is used. In our case total cooking time coincided with the time the slowest stove took to cook the meals allocated to it. Total fuel consumption $(\mathrm{kg})$ only refers to fuelwood.

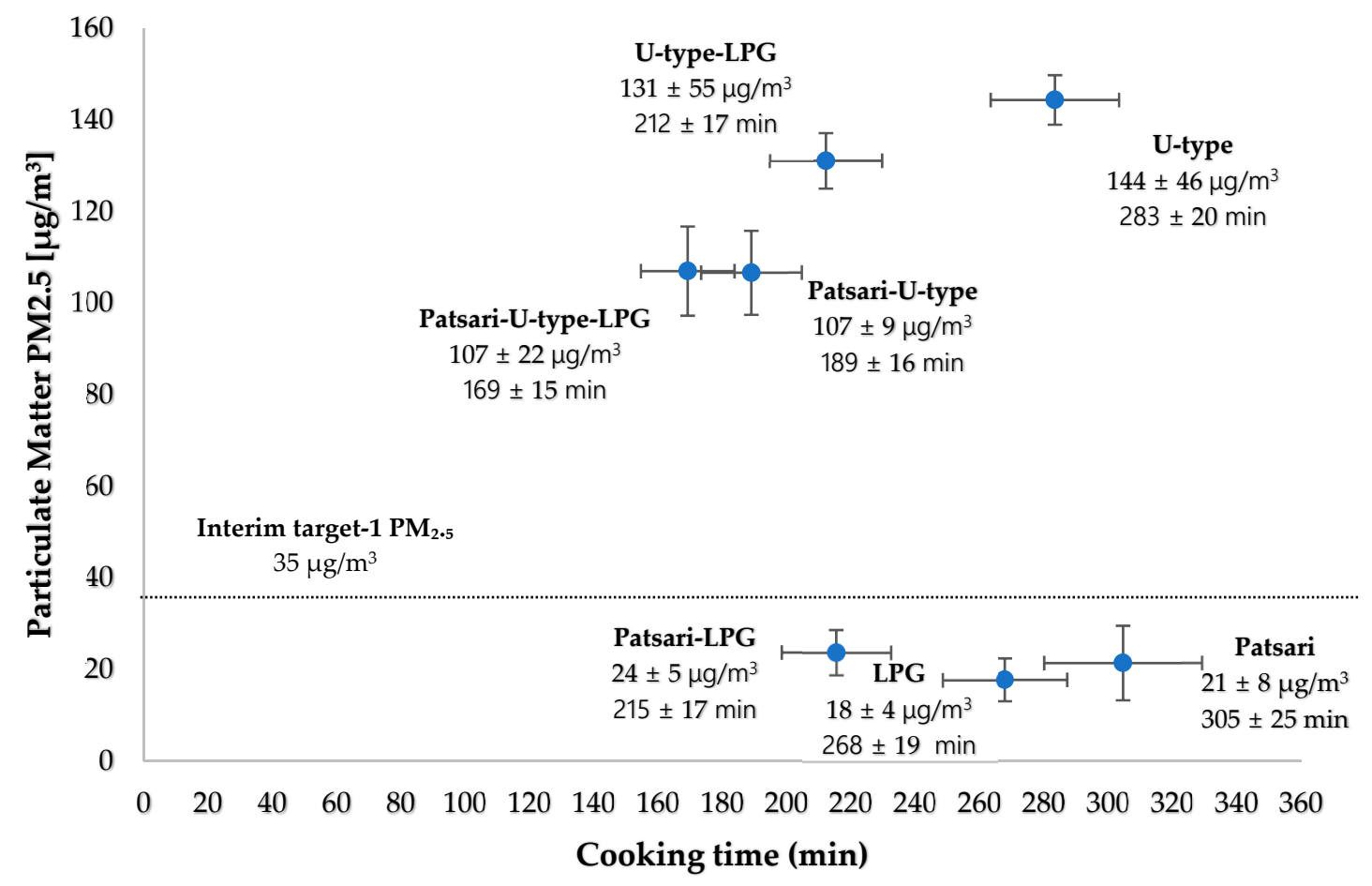

Figure 4. Cooking time and 24-h concentrations of $\mathrm{PM}_{2.5}$ for CCC. The blue dots represent concentration averages and whiskers are \pm 1 standard deviation of the measurements.

\section{Discussion}

\subsection{Indoor $\mathrm{CO}$ and $P M_{2.5}$ Concentrations}

Direct measurements of $\mathrm{PM}_{2.5}$ and $\mathrm{CO}$ concentrations during CCC in a test kitchen representative of local conditions demonstrated that the Patsari plancha-type chimney stove, either alone or in combination (stacking) with LPG stoves, results in kitchen concentrations that are below the annual 
concentration WHO Interim Target-1 (IT1) annual averages for $\mathrm{PM}_{2.5}$ and WHO 24-h guidelines for CO (Figure 3). These results support previous analyses while using the Single Zone Model [29] emissions inputs that were derived from local water boiling tests and field studies. Thus, the use of chimney stoves in low-density settlements—such as those typical in rural areas-represents a clear benefit to reduce the exposure to $\mathrm{PM}_{2.5}$ pollutants, as also concluded by Chartier et al. [30] and Tagle et al. [31]. In short, the Patsari and Patsari-LPG options constitute "clean stacking" alternatives for these settings.

Direct comparison to IWA stove performance tiers is less straightforward, as emissions performance targets are meant to be used with emission rates that were derived from laboratory performance testing. However, emissions rates that define tier 5 for fine particulate matter and for carbon monoxide align with the World Health Organization's Guidelines for indoor air quality: household fuel combustion [13]. Within this framework the incremental contributions of the stove to indoor air pollution are assessed while using the Single Zone Model, without incorporating ambient background concentrations, as these are regionally so variable and in many places with solid fuel use exceed WHO interim targets. Ambient $\mathrm{PM}_{2.5}$ concentration during the current set of measurements were, on average, $15 \pm 8 \mu \mathrm{g} / \mathrm{m}^{3}$. Therefore, the incremental contribution of the Patsari to 24-h average $\mathrm{PM}_{2.5}$ concentrations would be less than $10 \mu \mathrm{g} / \mathrm{m}^{3}$, or the air quality guideline used in tier 5 for reference (see Table 2). These results highlight that stove performance testing, and IWA frameworks, should be revised to incorporate the pervasive use of stove stacking and testing protocols that include controlled cooking cycles in test kitchens, as these are more representative of emissions during daily cooking activities.

Indoor air concentrations were within the range of field measurements of indoor air quality measured during uncontrolled cooking [27]. During 48-hr measurements of uncontrolled cooking while using U-type traditional stoves, $\mathrm{PM}_{2.5}$ kitchen concentrations were $257 \pm 176 \mu \mathrm{g} / \mathrm{m}^{3}$ as compared to current estimates of $144 \pm 46 \mu \mathrm{g} / \mathrm{m}^{3}$. Similarly, kitchen concentrations with the Patsari stove were $143 \pm 65 \mu \mathrm{g} / \mathrm{m}^{3}$ when compared to current estimates of $21 \pm 8 \mu \mathrm{g} / \mathrm{m}^{3}$ (however, in this latter case a small residual use of the open fire cannot be discarded). While measurements during uncontrolled cooking showed greater concentrations and variability than shown during the CCC in the simulated kitchen, this is not surprising; to facilitate comparisons between stacking options cooking tasks were performed by a single cook to reduce the variability that was introduced by different cooking and stove tending behaviors. However, as a consequence, the tests do not represent diverse cooking activities of different cooks in the region. Similarly, measurements were performed in a single simulated kitchen to facilitate comparisons between stacking options, and they do not capture the range of volume and ventilation rates that are present in actual homes in rural communities in the Purepecha region.

In addition, ambient concentrations during CCC in simulated kitchen were lower than those that were observed during uncontrolled cooking, which could account for the slightly lower concentrations seen with the open fires; however, in general, the results were comparable, which supports the use of the CCC in simulated kitchens as a tool to evaluate the implications of different stacking options. This is an important advance from using water boiling tests to perform comparisons [32] that have been shown not to represent emissions and fuel consumption [18] during daily cooking activities, and thus misrepresent the benefits of different cooking options.

\subsection{Stove Stacking Options}

The current study demonstrates that multi-level benefits-in terms of energy, fuel, and time savings - can be reached when clean technologies, such as LPG, are combined with improved stoves. As fuel and time savings constitute tangible benefits for local households, our study provides solid evidence on the reasons why stacking is preferred to exclusive use of stoves in most circumstances. Also, as the diverse local cooking practices differ largely in terms of the specific time and IAP emissions [18], identifying which practices traditionally carried out with the open fires are actually replaced by clean stoves within each stacking option (Table 1) is crucial to understanding the resultant IAP impacts.

The study confirms that exclusive use of LPG or clean fuels in rural Purepecha households is rare and stacking of stoves and fuels is more common. Overall, only $1 \%$ of these rural households that 
adopted LPG stoves used them exclusively; the rest stacked them in diverse configurations. Barriers to the exclusive use of clean cooking stoves in rural communities include high fuel prices for LPG [33], the fact that clean cookstoves rarely meet all of the energetic needs of a household [34] and different taste in meals [35] among other factors. Similar barriers have led to stacking in virtually all the regions of the world, including India [36], Rwanda [37], and other countries.

Given the widespread presence of stacking, estimating environmental and health implications of cookstoves by simply comparing one stove to another assuming total replacement will lead to misplaced expectations for stove programs, which will inevitably lead to disillusionment and a perceived failure of the program. More detailed comparisons of alternatives, or clean stacking options, in the light of user preferences will lead to more realistic outcomes, although perhaps not appearing as cost effective at the initial outset.

Finally, the current study shows a dynamic shifting between stoves and fuels for each cooking task, depending on what other stoves and fuels are present. Within each stacking option, there are definite patterns in terms of the cooking practices households prefer to be performed with each stove; however, these preferences shift, depending on the specific combination of stoves available to users. Therefore, the IAP, fuel, and environmental implications of adopting cleaner fuels and stoves cannot be predicted studying the stoves in isolation, but depend on the specific stacking options that dominate the mix. For example, when LPG is used in combination with TSF, only minor savings are achieved in terms of energy and no health benefits, because the clean stove only tends to be used for non-energy intensive tasks (e.g., reheating food at night or heating water for a tea). However, very substantial benefits are achieved if LPG is combined with Patsari stoves. The Patsari-LPG is the cleanest combination, as most uses of TSF are actually displaced with by the Patsari. In addition, the Patsari-LPG was also shown by Serrano-Medrano et al. [38] to be the one resulting in higher greenhouse gas mitigation when implemented at the country-scale to replace the use of TSF. This finding shows that the stacking of LPG stoves and improved chimney stoves provides users with substantially more health and environmental benefits with reduced cooking time than pursuing the exclusive use of LPG as in practice LPG promotion has led to stacking with TSF, with negligible benefits.

\subsection{Overall Implications}

Two major implications follow from the previous findings. First, cookstove programs widespread assumption of full displacement of one stove by another will lead to misplaced expectations. As such, analyses that estimate the environmental and health benefits assuming total replacement of traditional fires should not be conducted; rather, a thorough analysis of the stacking context and the implications of different options is needed. Second, it is critical to examine and promote "clean stacking" options, which are much more effective in displacing traditional fires. To achieve this, more emphasis is needed to understand the needs that are fulfilled by TSF, the different cooking practices, and how the different stoves perform relative to traditional alternatives regarding each practice. There is a need for implementation programs to shift focus from promoting single-stove and fuels to considering a more holistic evaluation of cooking, and improving kitchens, not just stoves and fuels.

Such programs could consider a menu of options that include better cooking practices (use of pressure cooker, taking the TSF outdoors, or drying the wood), the implementation of kitchen counters for food preparation, elevating stoves to prevent burns, including clean water provision and sanitation measures in kitchens, new fuels, and improved stoves. In particular, the use of chimney stoves will need to have a prominent role in these integrated programs, either as clean complements of TSF within the poorest rural households, to clean complements of LPG in more wealthy households due to their benefits in reducing indoor air pollution and exposures.

\subsection{Limitations}

Of course, there are some important limitations to the current analyses in the broader interpretation of the results, which highlights that similar analyses should be performed for different regional contexts: 
(i) Our CCC represents daily food items that are consumed in a representative rural household within the Purepecha Region of Michoacan. However, there is a wide range of dishes consumed in other regions of Mexico and further afield, and also variations in cooking sequences that were not captured in our study; (ii) the CCC was based on average family sizes for the Purepecha region, which might not be typical of other regions; (iii) The simulated kitchen was designed and constructed using representative parameters for regional kitchens (such as volume, size, materials and air exchange rates), but still there is large variability in rural Mexican kitchens; (iv) There are variations in manufacturing of different plancha stoves, and LPG burners that are not reflected by the current study; (v) The wood fuels used represent species and moisture contents that are commonly used in the Purepecha Region, but they may not be reflective of other regions; and, (vi) The current results do not capture the seasonal variations in temperature, relative humidity, and wind speed that may impact combustion conditions or ventilation rates in kitchens.

However, in spite of these limitations, the analyses that are presented here demonstrate the utility in using controlled cooking cycles to reflect the actual cooking practices in homes combined with test kitchens to evaluate environmental and health benefits between stacking options.

\section{Conclusions}

The present study helps to better assess the IAP impacts of different stacking patterns of stoves, practices, and fuel use in rural settings of developing countries. Several important policy and technical implications can be derived from this study:

- Evaluation of health and environmental consequences of stove transitions based on the full replacement of traditional fires will lead to misplaced expectations, and clean fuel and cookstove programs should evaluate more realistic "clean-stacking" options.

- The displacement of cooking tasks to other stoves depends on the specific stoves present. Thus, environmental and health implications of adopting cleaner fuels and stoves depend on the specific stacking options that dominate the mix.

- The promotion of LPG in rural households has resulted in stacking of open fires with LPG stoves, with negligible health benefits and marginal energy savings.

- Clean woodburning chimney stoves—such as the Patsari stove examined in this study-in combination with LPG could be the most effective stacking option in terms of IAP impacts and fuelwood savings.

- Stove performance testing frameworks should be revised to incorporate the pervasive use of stove stacking, and testing protocols that include controlled cooking cycles in test kitchens, as these are more representative of emissions during daily cooking activities.

Supplementary Materials: The following are available online at http://www.mdpi.com/2073-4433/10/11/693/s1, Figure S1: Purepecha Region of the Michoacan State; Figure S2: Simulated kitchen at GIRA facilities; Figure S3: Architectural plans of the prototype o simulated kitchen; Figure S4: Traditional dishes performed by CCC; Figure S5: IAP meters installation through simulated kitchen; Figures S6-S9: Main Cooking Practices by Stove and Stacking Option; Table S1: $\mathrm{PM}_{2.5}$ and CO 24-h concentrations, cooking tasks and ambient air for CCC; Table S2: Performance parameters for CCC.

Author Contributions: V.B., V.R.-G., O.M., R.E. and P.M. conceived and designed the experiments; B.O. participated in the design of the simulated kitchen; L.C. and P.M. carried out IAP measurements; A.S. contributed in both design and analysis of field survey; all conceived discussion and conclusions of this article.

Funding: This research was funded by the Clean Cooking Implementation Science Network (ISN), and by the Fondo de Sustentabilidad Energética SENER CONACYT grant number 2014246911.

Acknowledgments: The authors express their gratitude to all GIRA staff, Evaristo Herrera, Felix Patricio, Sarai Ramos, Dante Villanueva and Juan Vázquez for their help during entire emissions campaign, and also to Rosa from Santa Ana Chapitiro community for her valuable help in cooking tasks.

Conflicts of Interest: The authors declare no conflict of interest. 


\section{References}

1. WHO. Burning Opportunity: Clean Household Energy for Health, Sustainable Development, and Wellbeing of Women and Children; World Health Organization: Geneva, Switzerland, 2016.

2. GBD 2016 Risk Factors Collaborators. Global, regional, and national comparative risk assessment of 84 behavioural, environmental and occupational, and metabolic risks or clusters of risk, 1990-2016: A systematic analysis for the Global Burden of Disease Study 2016. Lancet 2017, 390, 1345-1422. [CrossRef]

3. Ruiz-Mercado, I.; Masera, O.; Zamora, H.; Smith, K.R. Adoption and sustained use of improved cookstoves. Energy Policy 2011, 39, 7557-7566. [CrossRef]

4. Ruiz-Mercado, I.; Masera, O. Patterns of Stove Use in the Context of Fuel-Device Stacking: Rationale and Implications. EcoHealth 2015, 12, 42-56. [CrossRef] [PubMed]

5. Shankar, A.V.; Quinn, A.; Dickinson, K.L.; Williams, K.; Masera, O.; Charron, D.; Darby, J. Everybody Stacks: Lessons from household energy case studies to inform design principles for clean energy transitions. Energy Policy 2019. under review.

6. Masera, O.; Bailis, R.; Drigo, R.; Ghilardi, A.; Ruiz-Mercado, I. Environmental burden of traditional bioenergy use. Annu. Rev. Environ. Resour. 2015, 40,121-150. [CrossRef]

7. Berrueta, B.; Serrano-Medrano, M.; García-Bustamante, C.; Astier, M.; Masera, O.R. Promoting sustainable local development of rural communities and mitigating climate change: The case of Mexico's Patsari improved cookstove Project. Clim. Chang. 2017, 140, 63-77. [CrossRef]

8. Masera, O.R.; Saatkamp, B.D.; Kammen, D.M. From linear fuel switching to multiple cooking strategies: A critique and alternative to the energy ladder model. World Dev. 2000, 28, 2083-2103. [CrossRef]

9. Medina, P.; Berrueta, V.; Martínez, M.; Ruiz, V.; Edwards, R.; Masera, O. Comparative performance of five Mexican plancha-type cookstoves using water boiling tests. Dev. Eng. 2017, 2, 20-28. [CrossRef]

10. Masera, O.; Diaz, R.; Berrueta, V.M. From cookstoves to cooking systems: The integrated program on sustainable household energy use in Mexico. Energy Sustain. Dev. 2005, 9, 25-36. [CrossRef]

11. Berrueta, V.; Edwards, R.; Masera, O.R. Energy performance of wood-burning cookstoves in Michoacan, Mexico. Renew. Energy 2008, 33, 859-870. [CrossRef]

12. Masera, O.R.; Navia, J. Fuel switching or multiple cooking fuels? Understanding inter-fuel substitution patterns in rural Mexican households. Biomass Bioenergy 1997, 12, 347-361. [CrossRef]

13. Johnson, M.; Edwards, R.; Berrueta, V.; Masera, O. New approaches to performance testing of improved cookstoves. Environ. Sci. Technol. 2010, 44, 368-374. [CrossRef] [PubMed]

14. Johnson, M.; Edwards, R.; Morawska, L.; Smith, K.; Nicas, M. WHO IAQ Guideline: Household Fuel Combustion. Review 3: Modeling Linking Emissions and Air Quality. 2016. Available online: https://www.who.int/airpollution/guidelines/household-fuel-combustion/Review_3.pdf (accessed on 13 March 2019).

15. Brooks, N.; Bhojvaid, V.; Jeuland, M.A.; Lewis, J.J.; Patange, O.; Pattanayak, S.K. How much do alternative cookstoves reduce biomass fuel use? Evidence from North India. Resour. Energy Econ. 2016, 43, 153-171. [CrossRef]

16. Romieu, I.; Riojas-Rodríguez, H.; Marrón-Mares, A.T.; Schilmann, A.; Perez-Padilla, R.; Masera, O. Improved Biomass Stove Intervention in Rural Mexico. Am. J. Respir. Crit. Care Med. 2009, 180, 649-656. [CrossRef]

17. Schilmann, A.; Riojas-Rodríguez, H.; Catalán-Vázquez, M.; Estevez-García, J.A.; Masera, O.; Berrueta, V.; Armendáriz-Arnez, C.; Pérez-Padilla, R.; Cortez-Lugo, M.; Rodríguez-Dozal, S.; et al. A follow-up study after an improved cookstove intervention in rural Mexico: Estimation of household energy use and chronic $\mathrm{PM}_{2.5}$ exposure. Environ. Int. 2019, 131, 105013. [CrossRef]

18. Medina, P.; Berrueta, V.; Martínez, M.; Ruiz, V.; Ruiz-Mercado, I.; Masera, O.R. Closing the gap between lab and field cookstove tests: Benefits of multi-pot and sequencing cooking tasks through controlled burning cycles. Energy Sustain. Dev. 2017, 41, 106-111. [CrossRef]

19. Pennise, D.; Charron, D.; Wofchuck, T.; Rouse, J.; Hunt, A. Evaluation of Manufactured Wood-Burning Stoves in Dadaab Refugee Camps, Kenya. Berkeley Air Monitoring Group 2010. Available online: http://www.safefuelandenergy.org/files/USAID\%20Daadab\%20study.pdf (accessed on 18 March 2019). 
20. Grabow, K.; Still, D.; Bentson, S. Test Kitchen studies of indoor air pollution from biomass cookstoves. Energy Sustain. Dev. 2013, 17, 458-462. [CrossRef]

21. MacCarty, N.; Still, D.; Ogle, D.; Drouin, T. Assessing Cook Stove Performance: Field and Lab Studies of Three Rocket Stoves Comparing the Open Fire and Traditional Stoves in Tamil Nadu, India on Measures of Time to Cook, Fuel Use, Total Emissions, and Indoor Air Pollution. Aprovecho Research Center. 2008. Available online: https:/www.k4health.org/sites/default/files/CCT\%20rocket\%20stove\%20report\%20India. pdf (accessed on 3 April 2019).

22. De la Sota, C.; Lumbreras, J.; Pérez, N.; Ealo, M.; Kane, M.; Youm, I.; Viana, M. Indoor air pollution from biomass cookstoves in rural Senegal. Energy Sustain. Dev. 2018, 43, 224-234. [CrossRef]

23. Instructions for Use of the Indoor Air Pollution Meter (IAP Meter) 5000 Series. Aprovecho Research Center. 2013. Available online: http://aprovecho.org/wp-content/uploads/2016/03/iap-meter-5000-series-instructionmanual.pdf (accessed on 1 April 2019).

24. Smith, K.R.; Dutta, K.; Chengappa, C.; Gusain, P.P.S.; Masera, O.; Berrueta, V.; Edwards, R.; Bailis, R.; Naumoff Shields, K. Monitoring and evaluation of improved biomass cookstove programs for indoor air quality and stove performance: Conclusions from the Household Energy and Health Project. Energy Sustain. Dev. 2007, 11, 5-18. [CrossRef]

25. Standard Operating Procedure. Installing Indoor Air Pollution Instruments in a Home; University of California-Berkeley: Berkeley, CA, USA, 2005; Available online: http://berkeleyair.com/wp-content/ publications/guidelines-for-instrument-placement.pdf (accessed on 17 August 2018).

26. National Ambient Air Quality Standards for Particulate Matter; Final Rule 40 CFR Part 50. Appendix L to Part 50-Reference Method for the Determination of Fine Particulate Matter as PM2.5 in the Atmosphere, July 1997. Available online: https://www3.epa.gov/ttnamti1/files/cfr/50apdxl.pdf (accessed on 30 July 2019).

27. Armendáriz-Arnez, C.; Edwards, R.D.; Johnson, M.; Rosas, I.A.; Espinosa, F.; Masera, O.R. Indoor particle size distributions in homes with open fires and improved Patsari cook stoves. Atmos. Environ. 2010, 44, 2881-2886. [CrossRef]

28. Masera, O.; Edwards, R.; Armendáriz-Arnez, C.; Berrueta, V.; Johnson, M.; Rojas Bracho, L.; Riojas-Rodríguez, H.; Smith, K. Impact of Patsari improved cookstoves on indoor air quality in Michoacán, Mexico. Energy Sustain. Dev. 2007, 11, 45-56. [CrossRef]

29. Johnson, M.; Lam, N.; Brant, S.; Gray, C.; Pennise, D. Modeling indoor air pollution from cookstove emissions in developing countries using a Monte Carlo single-box model. Atmos. Environ. 2011, 45, 3237-3243. [CrossRef]

30. Chartier, R.; Phillips, M.; Mosquin, P.; Elledge, M.; Bronstein, K.; Nandasena, S.; Thornburg, V.; Thornburg, J.; Rodes, C. A comparative study of human exposures to household air pollution from commonly used cookstoves in Sri Lanka. Indoor Air 2017, 27, 147-159. [CrossRef] [PubMed]

31. Tagle, M.; Smith, K.R.; Pillarisetti, A.; Hernández, M.T.; Leguizamón, L.; Galeano, A.C.; Flores, L.; Acosta, C.; Bergottini, A.; Dillner, A.; et al. Household Air Pollution from Biomass Burning in Urban and Rural Paraguay; University of California-Berkeley: Berkeley, CA, USA, 2018; Available online: https://static1.squarespace.com/static/53856e1ee4b00c6f1fc1f602/t/ 5add7e34562fa77ceb24693f/1524465216360/Study+biomass+cooking+Paraguay_final_ENG.pdf (accessed on 17 April 2019).

32. Ruiz-García, V.M.; Edwards, R.D.; Ghasemian, M.; Berrueta, V.M.; Princevac, M.; Vázquez, J.C.; Johnson, M.; Masera, O.R. Fugitive Emissions and Health Implications of Plancha-Type Stoves. Environ. Sci. Technol. 2018, 52, 10848-10855. [CrossRef]

33. Wolf, J.; Mäusezahl, D.; Verastegui, H.; Hartinger, S.M. Adoption of Clean Cookstoves after Improved Solid Fuel Stove Programme Exposure: A Cross-Sectional Study in Three Peruvian Andean Regions. Int. J. Environ. Res. Public Health 2017, 14, 745. [CrossRef]

34. Rehfuess, E.A.; Puzzolo, E.; Stanistreet, D.; Pope, D.; Bruce, N. Enablers and barriers to large-scale uptake of improved solid fuel stoves: A systematic review. Environ. Health Perspect. 2014, 122, 120-130. [CrossRef]

35. Young, B.N.; Clark, M.L.; Rajkumar, S.; Benka-Coker, M.L.; Bachand, A.; Brook, R.D.; Nelson, T.L.; Volckens, J.; Reynolds, S.J.; L'Orange, C.; et al. Exposure to household air pollution from biomass cookstoves and blood pressure among women in rural Honduras: A cross-sectional study. Wiley 2018, 16, 328-338. [CrossRef]

36. Gould, C.F.; Urpelainen, J. LPG as a clean cooking fuel: Adoption, use, and impact in rural India. Energy Policy 2018, 122, 395-408. [CrossRef] 
37. Jagger, P.; Das, I. Implementation and scale-up of a biomass pellet and improved cookstove enterprise in Rwanda. Energy Sustain. Dev. 2018, 46, 32-41. [CrossRef]

38. Serrano-Medrano, M.; García-Bustamente, C.; Berrueta, V.M.; Martínez-Bravo, R.; Ruiz-García, V.M.; Ghilardi, A.; Masera, O. Promoting LPG, clean woodburning cookstoves or both? Climate change mitigation implications of integrated household energy transition scenarios in rural Mexico. Environ. Res. Lett. 2018, 13, 1-14. [CrossRef]

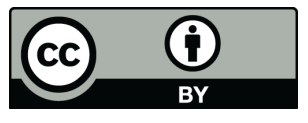

C 2019 by the authors. Licensee MDPI, Basel, Switzerland. This article is an open access article distributed under the terms and conditions of the Creative Commons Attribution (CC BY) license (http://creativecommons.org/licenses/by/4.0/). 